\title{
Physiological Responses of Microcystis aeruginosa to Extracellular Degradative Enzymes and Algicidal Substance from Heterotrophic Bacteria
}

\author{
Qing Zhou, 2, 3, Yingying Zhang1, 2,3, Shiqun Han ${ }^{1,2}$, Yan Wang,, \\ Hongjie Qin ${ }^{1,2}$, Zhiyong Zhang, 2,3* \\ ${ }^{1}$ Institute of Agricultural Resources and Environment, Jiangsu Academy of Agricultural Sciences, \\ Nanjing 210014, China \\ ${ }^{2}$ Key Laboratory of Agro-Environment in Downstream of Yangze Plain, Ministry of Agriculture and Rural Affairs \\ of the People's Republic of China, Nanjing 210014, China \\ 3 Jiangsu University, Zhenjiang 212013, China
}

Received: 15 July 2020

Accepted: 25 September 2020

\begin{abstract}
It is a promising way to control Microcystis bloom by the algicidal substances from some special heterotrophic bacteria. However, the algicidal mechanism of the common known 1-hydroxyphenazine and the potential impact of extracellular degradative enzymes from total accompanying heterotrophic bacteria on its algicidal characteristics remains unknown. Here, the physiological changes of Microcystis aeruginosa were investigated under the stress of 1-hydroxyphenazine and extracellular degradative enzymes individually or together. The results showed that the extracellular degradative enzymes from heterotrophic bacteria had a weak inhibitory effect on the growth of $M$. aeruginosa and made $M$. aeruginosa suffered oxidative damage. 1-hydroxyphenazine promoted the cells death of $M$. aeruginosa with a manner independent of reactive oxygen species (ROS) level. 1-hydroxyphenazine might play a role in promoting the cyclic electron transport to reduce ROS in M. aeruginosa. The reduction of total anti-oxidative capacity and the depletion of glutathione might induce the death of M. aeruginosa under stress of 1-hydroxyphenazine. The addition of extracellular degradative enzymes eventually delayed the algae death and alleviated the inhibitory effect of 1-hydroxyphenazine on algal ATPase hydrolytic activity and total antioxidant capacity. The heterotrophic partnership seemed to be helpful to increase the stress resistance of M. aeruginosa.
\end{abstract}

Keywords: Microcystis aeruginosa, heterotrophic bacteria, extracellular enzymes, algicidal substance, 1-hydroxyphenazine, heterotrophic partnership

*e-mail: jaaszyzhang@126.com 


\section{Introduction}

As global warming and eutrophication of water bodies, cyanobacteria blooms are boosted [1]. A series of environmental problems have been aroused worldwide, such as water hypoxia, release of toxic secondary metabolites [2]. Toxigenic Microcystis aeruginosa is a primary bloom-forming cyanobacteria in the world [3]. Because of the hepatotoxicity and potential hepatocarcinogenicity of microcystins, much attention has been focused on M. aeruginosa.

Heterotrophic bacteria are important members accompanying cyanobacteria in aquatic ecosystem. About $14 \%$ of organic carbon required by heterotrophic bacteria are provided by extracellular organic carbon from phytoplankton [4]. M. aeruginosa can be considered as incubator for heterotrophic bacteria when it becomes dominant in phytoplankton in eutrophic water [5]. Colonial M. aeruginosa cells are surrounded by thick surface layer which is mainly composed of polysaccharides and proteins. Materials in surface layer can be absorbed by algae itself and also be used by heterotrophic bacteria [6]. Furthermore, many members of heterotrophic bacteria are active in the decomposition of Microcystis [7].

Some Microcystis-lying bacteria are found among heterotrophic bacteria associated with Microcystis bloom [8]. Their number is directly related to the density of algae [9]. However, the control of cyanobacteria is dependent on a density threshold at which algicidal bacteria can release lytic substances and induce algal cell disruption [10]. It is a promising way to control Microcystis bloom by the lytic substances because of the breakthrough of density limitation. Nowadays, many lytic substances against cyanobacteria have been identified from bacterial exudate [8]. Although some algicidal substances have been revealed to damage the algae cell wall and elevate the reactive oxygen species (ROS) and malondialdehyde in algae cell [11-12], it is not enough. The lytic mechanism of many known algicidal subtances with different structures against cyanobacteria has not been thoroughly explored. Pseudomonas aeruginosa is a common known algicidal bacterium in the colonies of $M$. aeruginosa. 1-hydroxyphenazine as a relatively stable and algicidal substance was identified from $P$. aeruginosa [13-14]. But little is known about how its algicidal subtances such as 1-hydroxyphenazine inhibit the growth of $M$. aeruginosa.

Colonial $M$. aeruginosa cells are found to be less sensitive to algicidal bacteria than unicellular cells in lab [15]. Thick surface layer may act as buffers against some damages [16]. However, the concentration of total heterotrophic bacteria are on average 23 times as much as cyanobacteria in eutrophic waters [17]. The activities of extracellular degradative enzymes from heterotrophic bacteria can rapidly increase with the activity of algal photosynthesis [18]. Moreover, the role of heterotrophic bacteria can be further enhanced because of higher dissolved organic carbon concentrations resulted from mixing events or high flows [19]. Whether extracellular degradative enzymes of total heterotrophic bacteria can interfere with the buffering effect of algal surface layer and promote the algicidal effect remains unknown.

The aims of this study were to explore the physiological changes of $M$. aeruginosa under stress of 1-hydroxyphenazine and the influence of extracellular degradative enzymes from heterotrophic bacteria on these algicidal characteristics. For this, the cells density, oxidative stress, energy status, intracellular iron-binding capacity and fructose 1, 6-diphosphatase activity of $M$. aeruginosa were investigated under the stress of 1-hydroxyphenazine and extracellular degradative enzymes from heterotrophic bacteria individually or together. We hope it is helpful to make better use of algicidal substances to control cyanobacteria bloom.

\section{Materials and Methods}

\section{Strain and Culturing Conditions}

The microcystin-producing strain Microcystis aeruginosa (FACHB-912) was obtained from Institute of Hydrobiology, Chinese Academy of Sciences (Wuhan, China). This strain was cultured in $10 \%$ modified Hoagland's medium ( $\mathrm{pH}$ 7.0) [20] supplemented with $\mathrm{Ca}^{2+}$ at a final concentration of $36 \mathrm{mg} \mathrm{L}^{-1}$ in incubator to maintain colonial status. Medium was autoclaved at $121^{\circ} \mathrm{C}$ for $20 \mathrm{~min}$ before used. The incubator was maintained at $28^{\circ} \mathrm{C}$ with a constant relative humidity of $75 \%$ and illuminated with the density of $200 \mu \mathrm{mol}$ photons $\mathrm{m}^{-2} \mathrm{~s}^{-1}$ in 12-hour diurnal cycles.

\section{Preparation of Extracellular Degradative Enzymes}

The heterotrophic bacteria was obtained from surface sediment-water mixture of Taihu lakeside wetland in Yixing (China) where was suffered from Microcystis bloom. Heterotrophic bacteria was enriched in the same $10 \%$ modified Hoagland's medium ( $\mathrm{pH} 7.0)$ which was supplemented with tryptone $\left(2 \mathrm{~g} \mathrm{~L}^{-1}\right)$, yeast extract $\left(2 \mathrm{~g} \mathrm{~L}^{-1}\right)$ and $\mathrm{NaCl}\left(1 \mathrm{~g} \mathrm{~L}^{-1}\right)$. The community structure of these culturable bacteria was shown in Fig. 1 by analysis of high-throughput sequencing at Shanghai Personal Biotechnology Co., Ltd. (China). The main culturable bacteria belonged to proteobacteria. After cultured at $28^{\circ} \mathrm{C}$ for $18 \mathrm{~h}$ with shaking at $100 \mathrm{rpm}$, cells were discarded from culture fluids by centrifugation at $4^{\circ} \mathrm{C}$, $8000 \mathrm{~g}$ for $15 \mathrm{~min}$. Then, extracellular enzymes was precipitated from non-cell culture fluids by ammonium sulfate $(60 \%$ saturation). Enzymes precipitate was dissolved in $10 \mathrm{mM}$ HEPES buffer ( $\mathrm{pH} 7.0$ ), dialyzed in the same HEPES buffer for 6 hours at $4^{\circ} \mathrm{C}$ and dialyzed again in $10 \%$ modified Hoagland's medium $(\mathrm{pH} 7.0)$ for overnight at $4^{\circ} \mathrm{C}$. These buffer and medium used for dialysis were autoclaved at $121^{\circ} \mathrm{C}$ for $20 \mathrm{~min}$. Enzymes 


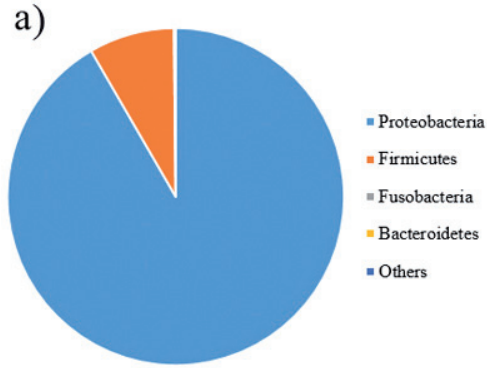

Relative abundance at phylum level (\%) b)

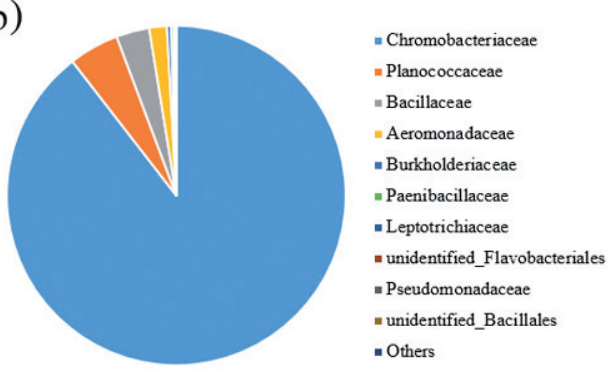

Relative abundance at family level (\%)

Fig. 1. The community structure of the culturable bacteria.

concentration was determined by the Bradford method using BSA as a standard.

\section{Experimental Design}

M. aeruginosa was amplified in $10 \%$ modified Hoagland's medium supplemented with $\mathrm{Ca}^{2+}$ for 7 days and then transferred into aseptic conical flasks $(2 \mathrm{~L})$ when it was at exponential growth phase $\left(5.37 \times 10^{6}\right.$ cells $\left.\mathrm{ml}^{-1}\right)$. Next then, 1-hydroxyphenazine (purity $>99 \%$, Tokyo Chemical Industry Co., Ltd., Japan) and extracellular enzymes were then respectively added into $M$. aeruginosa cultures in flasks at final concentration of $5.00 \mathrm{mg} \mathrm{L}^{-1}$ and $1.75 \mathrm{mg} \mathrm{L}^{-1}$ with the exposure time from 0 to 4 days, while the $M$. aeruginosa cultures without 1-hydroxyphenazine and extracellular enzymes were used as controls (Fig. 2). The dose of 1-hydroxyphenazine was selected based on its lower concentration for effective growth inhibition of $M$. aeruginosa in our preliminary experiments. The amount of extracellular enzymes was applied according to the secretion of heterotrophic bacteria at the concentration of $1.07 \times 10^{7}$ cells $\mathrm{ml}^{-1}$ which was close to the bacterial density in cyanobacteria-blooming Taihu Lake in summer. Samples were taken for analysis of algal density and physiological parameters at 1-day interval. All experiments were conducted with three independent replicates. The culture fluids were stirred at $300 \mathrm{rpm}$ for $5 \mathrm{~min}$ twice a day by magnetic force. All treatments were cultivated under the culturing conditions described above.

\section{Measurement of Algae Density}

Algae fluids were used for analysis. Algae cells were counted on a hemocytometer using a microscope (XS-213; Jiangnan Optical Instrument Factory, Nanjing, China), after stained with Lugol's iodine solution.

\section{Determination of Physiological Parameters}

Algae cells were harvested by centrifugation at $4^{\circ} \mathrm{C}, 5000 \mathrm{~g}$ for $5 \mathrm{~min}$, washed with $10 \mathrm{mM}$ HEPES buffer $(\mathrm{pH}$ 7.0) and resuspended in same HEPES buffer. The ultrasonic cell lysate was cleared of cell debris using centrifugation at $4^{\circ} \mathrm{C}, 8000 \mathrm{~g}$ for
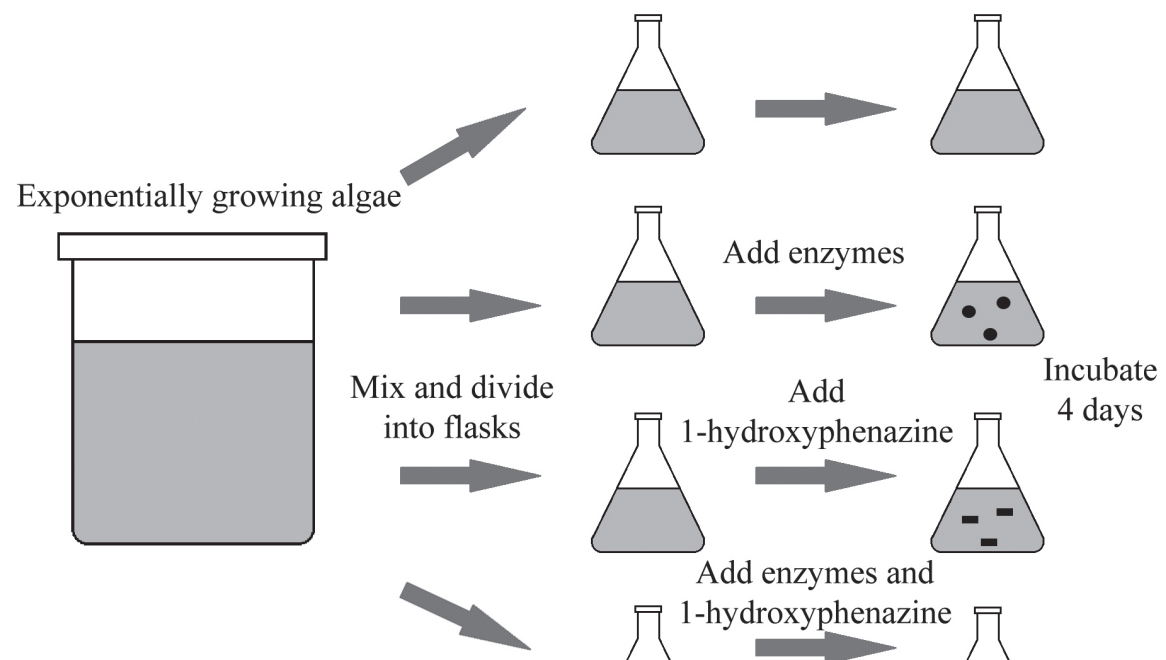

Add enzymes and

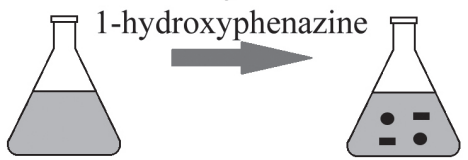

Fig. 2. Schematic diagram of the experimental procedure. 
$10 \mathrm{~min}$ and then used for analysis of physiological parameters. Protein concentration was quantified by the Bradford method using BSA as a standard. Total antioxidative capability (T-AOC) was measured by ferric ion reduction method using the T-AOC detection kit (Jiancheng Bioengineering Institute, China). The total glutathione (T-GSH) content was assayed by 5 , 5'-dithio-bis-(2-nitrobenzoic acid) (DTNB) method using a commercial kit (Jiancheng Bioengineering Institute, China). Malondialdehyde (MDA) content was detected by thibabituric acid (TBA) method using a commercial kit (Jiancheng Bioengineering Institute, China). The content of nitrotyrosine-containing proteins was determined by competitive enzyme immunoassay method using OxiSelectTM nitrotyrosine ELISA kit (Cell Biolabs Inc., USA). ATP content was determined by phosphomolybdic acid clolrimetric method using a commercial kit (Jiancheng Bioengineering Institute, China). Total ATPase hydrolytic activity was detected by the method of inorganic phosphate determination using ultramicro total ATPase assay kit (Jiancheng Bioengineering Institute, China). Fructose 1, 6-diphosphatase (FBPase) activity was assayed by double antibody sandwich method using a commercial ELISA kit (Jiangsu Feiya Biotechnology Co., Ltd, China). Total iron-binding capacity (TIBC) was measured by bipyridine colorimetric method using a commercial kit (Jiancheng Bioengineering Institute, Nanjing, China). All procedures were performed in accordance with manufacturer's instructions. All assays were carried out in triplicate.

\section{Statistical Analysis}

Data were presented as mean \pm standard deviation (SD). Differences between controls and treatments were determined by one-way ANOVA. Pearson correlation analysis was used to analyze the correlation among parameters. Linear regression analysis was used to test the relationship. Statistical significances were conformed at $p<0.05$. All statistical analyses were performed using IBM SPSS Statistics 20.0 (IBM SPSS Inc., USA).

\section{Results}

\section{Effect of Extracellular Degradative Enzymes and Algicidal Substance from Bacteria on the Growth of M. aeruginosa}

When extracellular enzymes and 1-hydroxyphenazine from heterotrophic bacteria were exposed to $M$. aeruginosa separately or together, the algal growth was found inhibited to different extents compared to the controls (Fig. 3). Algae density was significantly lower in enzymes treatments than that in controls after 3 days. Algae cell death was triggered both in 1-hydroxyphenazine treatments and in combined

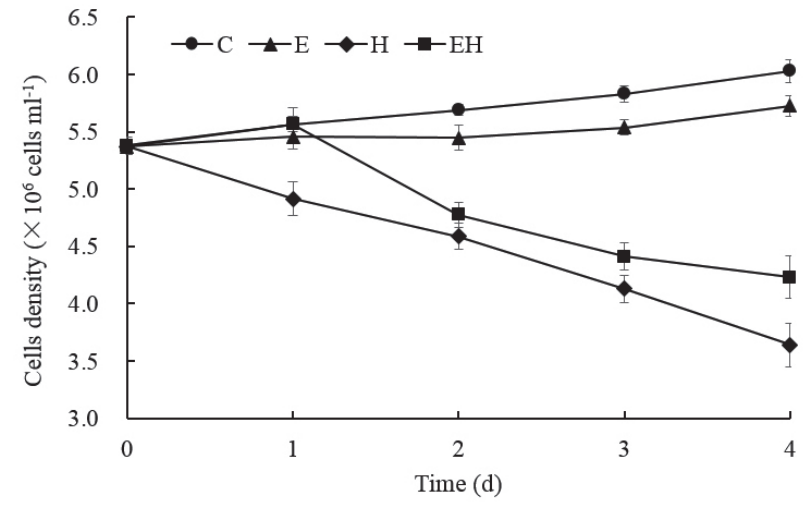

Fig. 3. Effect of extracellular degradative enzymes and 1-hydroxyphenazine from bacteria on the growth of $M$. aeruginosa. C: control; E: enzymes treatments; $\mathrm{H}$ : 1-hydroxyphenazine treatments; EH: combined treatments of enzymes and 1-hydroxyphenazine.

treatments of enzymes and 1-hydroxyphenazine (hereafter called combined treatments). However, the remaining algae density was notably higher in combined treatments than that in 1-hydroxyphenazine treatments after 3 days.

\section{Effect of Extracellular Degradative Enzymes and Algicidal Substance from Bacteria on Oxidative Stress of $M$. aeruginosa}

Compared with controls, algal MDA content was apparently elevated by a maximum of $136 \%$ in enzymes treatments (Fig. 4a). But algal MDA content in 1-hydroxyphenazine treatments and combined treatments were both close to controls. There was not significant differences between 1-hydroxyphenazine treatments and combined treatments. Correlation analysis revealed that algal MDA content had notably negative linear correlation with algae density in controls $(\mathrm{r}=-0.678, p<0.05)$, while it had notably positive linear correlation with algae density in 1-hydroxyphenazine treatments $(\mathrm{r}=0.912, p<0.05)$ and combined treatments $(\mathrm{r}=0.822, p<0.05)$. But this correlation was not significant in enzymes treatments.

Algal nitrotyrosine-containing proteins level in enzymes treatments was significantly higher than that in controls after 2 days, and then dropped to controls level at day 4 (Fig. 4b). Algal nitrotyrosine-containing proteins level in combined treatments was similar to that of controls. Algal nitrotyrosine-containing proteins level in 1-hydroxyphenazine treatments was not significantly different from controls level until 4 days later. Correlation analysis showed that algal nitrotyrosine-containing proteins level had significantly negative linear correlation with algae density in controls ( $\mathrm{r}=-0.645, p<0.05)$, while that had significantly positive linear correlation with algae density in combined treatments $(\mathrm{r}=0.630, p<0.05)$. But this 
a)

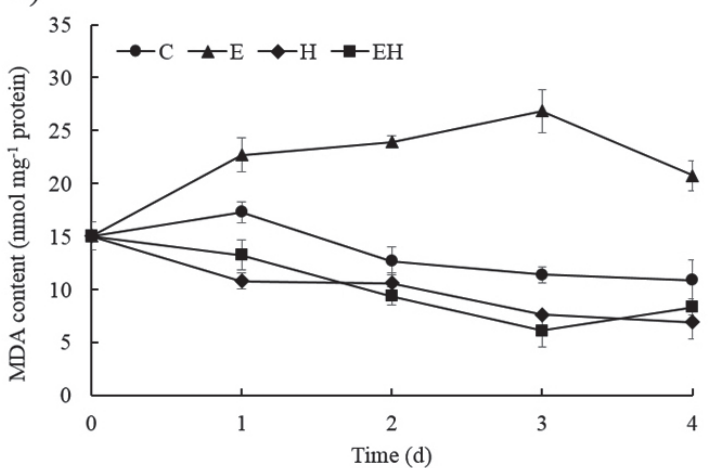

c)

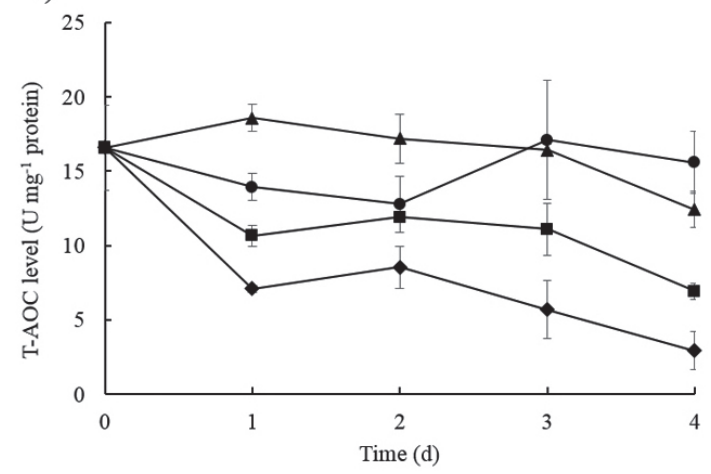

b)

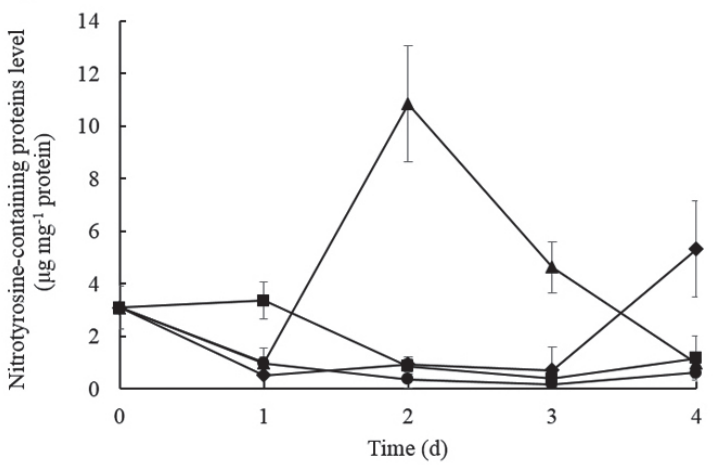

d)

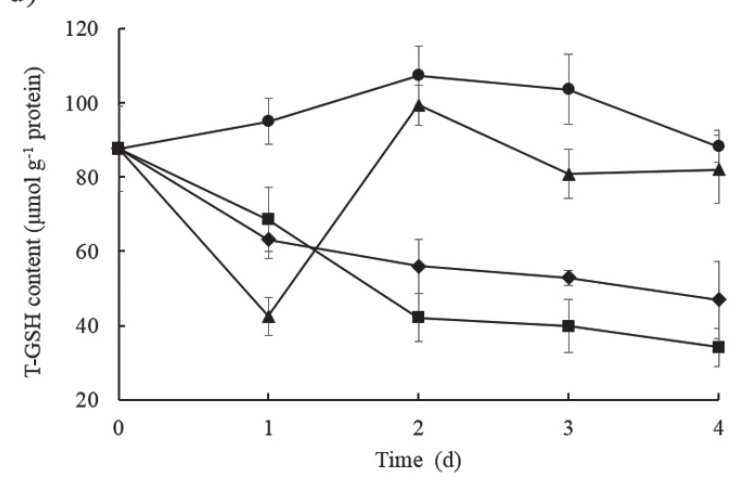

Fig. 4. Effect of extracellular degradative enzymes and 1-hydroxyphenazine from bacteria on oxidative stress of M. aeruginosa. a) MDA content; b) Nitrotyrosine-containing proteins level; c) T-AOC level; d) T-GSH content. C: control; E: enzymes treatments; H: 1-hydroxyphenazine treatments; EH: combined treatments of enzymes and 1-hydroxyphenazine.

correlation was not significant in enzymes treatments and 1-hydroxyphenazine treatments.

Algal T-AOC in controls was kept in a dynamic balance. Algal T-AOC in enzymes treatments was only notably higher than that in controls at day 2 and then dropped to controls level (Fig. 4c). Algal T-AOC in 1-hydroxyphenazine treatments was significantly lower than that in controls at day 1, 3 and 4. Although Algal T-AOC in combined treatments was significantly lower than that in controls at last, it was still significantly higher than that in 1-hydroxyphenazine treatments. Correlation analysis indicated that algal T-AOC had significantly positive linear correlation with algae density in1-hydroxyphenazine treatments $(\mathrm{r}=0.828$, $p<0.05)$ and combined treatments ( $\mathrm{r}=0.598, p<0.05)$. But this correlation was not significant in controls and enzymes treatments.

Algal T-GSH content in controls was also maintained at a dynamic balance. Algal T-GSH content in enzymes treatments was cut down fleetly and then recovered to controls level (Fig. 4d). Algal T-GSH content no matter in 1-hydroxyphenazine treatments or in combined treatments was significantly lower than that in controls. But there was not significant differences between 1-hydroxyphenazine treatments and combined treatments. Correlation analysis revealed that algal T-GSH content had significantly positive linear correlation with algae density in1- hydroxyphenazine treatments $(\mathrm{r}=0.763, p<0.05)$ and combined treatments $(\mathrm{r}=0.843, p<0.05)$. But this correlation was not significant in controls and enzymes treatments.

\section{Effect of Extracellular Degradative Enzymes and Algicidal Substance from Bacteria on Intracellular Iron-Binding Capacity of $M$. aeruginosa}

As shown in Fig. 5, algal TIBC was significantly reduced by a maximum of $55 \%$ in enzymes treatments compared to controls. Algal TIBC in 1-hydroxyphenazine treatments was significantly less than that in enzymes treatments after 2 days. Algal TIBC was notably reduced by a maximum of $85 \%$ in 1-hydroxyphenazine treatments compared to control. But there was not significant differences between 1-hydroxyphenazine treatments and combined treatments. Correlation analysis showed that algal TIBC had significantly positive linear correlation with algae density in 1-hydroxyphenazine treatments $(\mathrm{r}=0.836, p<0.05)$ and combined treatments $(\mathrm{r}=0.652$, $\mathrm{p}<0.05$ ), while that had significantly negative linear correlation with algae density in enzymes treatments $(\mathrm{r}=-0.643, p<0.05)$. But this correlation was not significant in controls. 


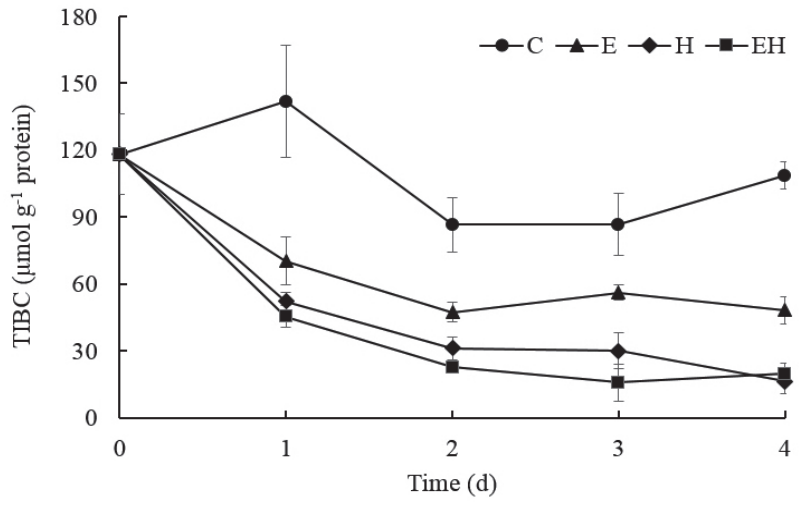

Fig. 5. Effect of extracellular degradative enzymes and 1-hydroxyphenazine from bacteria on intracellular iron-binding capacity of $M$. aeruginosa. C: control; E: enzymes treatments; $\mathrm{H}$ : 1-hydroxyphenazine treatments; EH: combined treatments of enzymes and 1-hydroxyphenazine.

\section{Effect of Extracellular Degradative Enzymes and Algicidal Substance from Bacteria on FBPase Activity of $M$. aeruginosa}

As shown in Fig. 6, algal FBPase activity in enzymes treatments was close to that in controls with no significant difference. Algal FBPase activity was apparently promoted in 1-hydroxyphenazine treatments compared to controls. But algal FBPase activity in combined treatments was increased one day later than that in 1-hydroxyphenazine treatments. And finally, algal FBPase activity in combined treatments was significantly lower than that in 1-hydroxyphenazine treatments. Correlation analysis indicated that algal FBPase activity had significantly negative linear correlation with algae density in 1-hydroxyphenazine treatments $(\mathrm{r}=-0.975, p<0.05)$ and combined treatments $(\mathrm{r}=-0.921, p<0.05)$. But this correlation was not significant in controls and enzymes treatments.

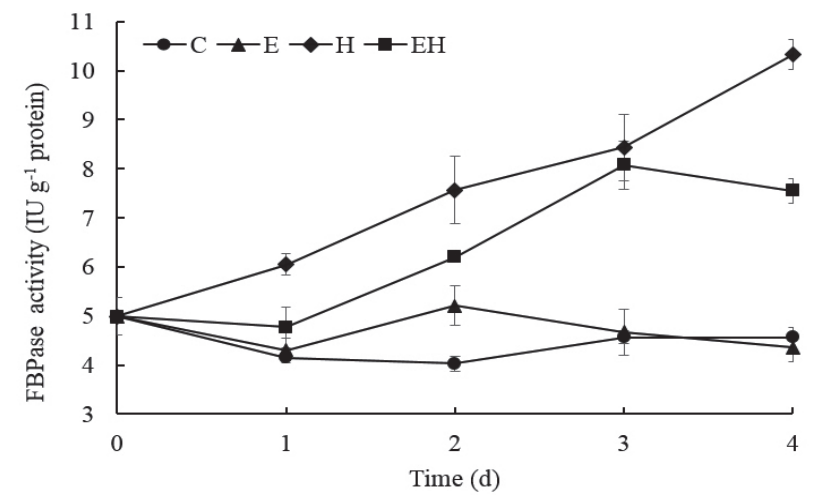

Fig. 6. Effect of extracellular degradative enzymes and 1-hydroxyphenazine from bacteria on FBPase activity of $M$. aeruginosa. C: control; E: enzymes treatments; $\mathrm{H}$ : 1-hydroxyphenazine treatments; EH: combined treatments of enzymes and 1-hydroxyphenazine.

\section{Effect of Extracellular Degradative Enzymes and Algicidal Substance from Bacteria on Energy Balance of $M$. aeruginosa}

Algal ATP level in enzymes treatments and in combined treatments were both not significantly different from that of controls (Fig. 7a). Algal ATP level in 1-hydroxyphenazine treatments was fleetly increased and then recovered to controls level. Correlation analysis indicated that algal ATP level had significantly positive linear correlation with algae density in controls $(\mathrm{r}=0.594, p<0.05)$. But this correlation was not significant in any other treatments.

Algal ATPase hydrolytic activity in enzymes treatments was kept at the same level of controls after a short promotion (Fig. 7b). Algal ATPase hydrolytic activity in 1-hydroxyphenazine treatments was gradually inhibited and was significantly lower than that in controls after 2 days. Algal ATPase hydrolytic activity in combined treatments was finally significantly inhibited after a short promotion. But algal ATPase hydrolytic activity in combined treatments was still apparently higher than that in 1-hydroxyphenazine treatments over time. Correlation analysis showed that algal ATPase hydrolytic activity had significantly positive linear correlation with algae density in 1-hydroxyphenazine treatments $(\mathrm{r}=0.882, p<0.05)$ and combined treatments $(\mathrm{r}=0.742, p<0.05)$. But this correlation was not significant in controls and enzymes treatments.

\section{Discussion}

1-hydroxyphenazine showed a strong algicidal activity. Cells death in $M$. aeruginosa was apparently promoted under the stress of 1-hydroxyphenazine. Many algicidal substances were known to mainly promote the production of ROS, lead to oxidative damage of cellular components, interfere with the photosynthesis and result in the lack of energy [21-22]. But the algicidal mode of 1-hydroxyphenazine was a little different. When algal cell death occurred under the stress of 1-hydroxyphenazine, the MDA content of $M$. aeruginosa did not increase and the nitrotyrosinecontaining proteins level of $M$. aeruginosa was not elevated until day 4. MDA and nitrotyrosinecontaining proteins were usually used as biomarkers to reflect oxidative damage of cells by ROS [23-24]. Furthermore, when algal cell death occurred under the stress of 1-hydroxyphenazine, algal ATP content was still maintained at a dynamic balance and eventually closed to controls. FBPase was a key regulatory enzyme in the Calvin cycle of cyanobacteria for carbon fixation. FBPase gene was reported essential to sustain growth for cyanobacteria [25]. Overexpression of FBPase was proved to increase the growth of cyanobacteria [26]. FBPase was also considered as the target for some algicides to control algal blooms. But 
a)

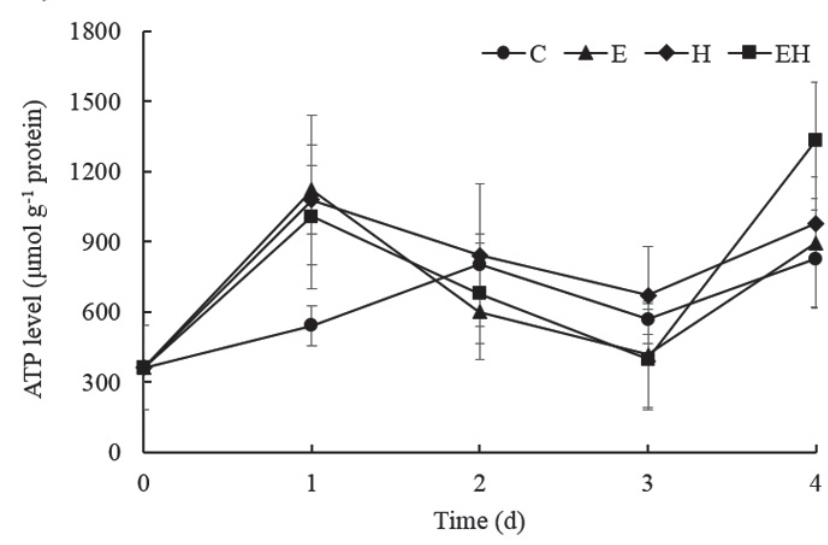

b)

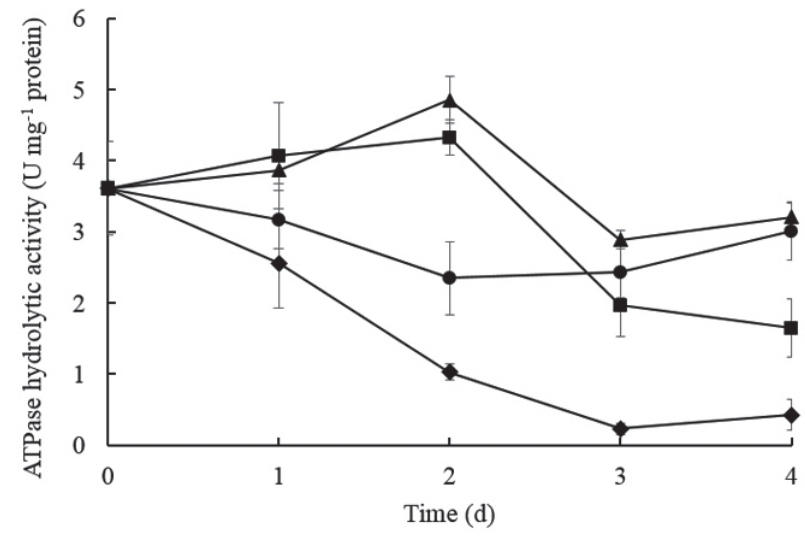

Fig. 7. Effect of extracellular degradative enzymes and 1-hydroxyphenazine from bacteria on energy balance of M. aeruginosa. a) ATP level; b) ATPase hydrolytic activity. C: control; E: enzymes treatments; H: 1-hydroxyphenazine treatments; EH: combined treatments of enzymes and 1-hydroxyphenazine.

our results indicated that FBPase was not the target of 1-hydroxyphenazine. FBPase has been found to be sensitive to the AMP:ATP ratio [27]. Our data showed that ATPase hydrolytic activity of $M$. aeruginosa was severely inhibited by 1-hydroxyphenazine. That was likely to reduce the production of AMP and result in the stimulation of FBPase. Previous research found that Scenedesmus obliquus (green algae) was able to undergo inhibition in a ROS-independent manner [28]. HeLa cells and Escherichia coli were also reported to undergo apoptosis with a manner independent of ROS level, but dependent on GSH depletion [29-30]. Based on our data, it was assumed that the reduction of total anti-oxidative capacity and the depletion of GSH might induce the death of $M$. aeruginosa under the short-term stress of 1-hydroxyphenazine.

The extracellular degradative enzymes from heterotrophic bacteria showed an inhibitory effect on the growth of $M$. aeruginosa and made $M$. aeruginosa suffered oxidative damage. These results were consistent with that of some heterotrophic bacteria acting on cyanobacteria [31-32]. The accumulation of ROS was found to be closely related to the rate of photosynthetic electron transport [33]. But flavodoxin level in cyanobacteria was found to be elevated under iron deficiency and was then conducive to scavenging ROS [34]. Synechococcus sp. (cyanobacteria) was reported to downregulate the genes that encoded iron-rich proteins when co-cultured with Vibrio parahaemolyticus [35]. According to our data, lower TIBC of M. aeruginosa might reflect a physiological iron-deficiency in 1-hydroxyphenazine treatments and combined treatments. However, the TIBC of $M$. aeruginosa in enzymes treatments was also reduced a little compared to controls. Therefore, flavodoxin might not be the main factor which led to ROS reduction in 1-hydroxyphenazine treatments and combined treatments. In addition, there existed photosystem I-NAD $(\mathrm{P}) \mathrm{H}$ dehydrogenase cyclic electron flow in cyanobacteria which only produced ATP [36]. The oxidative stress could be alleviated by the enhancement of cyclic electron transport [37]. Based on the status of algal cellular ATP pool in our experiments, it was likely that 1-hydroxyphenazine might enhance the cyclic electron transport in M. aeruginosa and extracellular degradative enzymes could not prevent the effect of 1-hydroxyphenazine on the cyclic electron transport. This assumption needed to be further tested. Moreover, it was interesting that cells death of $M$. aeruginosa was delayed and alleviated even when they were oppressed by the double role of 1-hydroxyphenazine and extracellular degradative enzymes, compared to 1-hydroxyphenazine treatments. The addition of extracellular degradative enzymes eventually alleviated the inhibitory effect of 1-hydroxyphenazine on ATPase hydrolytic activity and total antioxidant capacity. Contrary to our original assumption, these data seemed to support that heterotrophic partnership was helpful to increase the stress resistance of $M$. aeruginosa. In order to get the same inhibitory effect on Microcystis, more algicidal substances might be needed in the environment with accompanying bacteria. Although there were some differences between culturable bacteria and natural bacteria communities, it was a meaningful attempt to distinguish the different roles of extracellular degradative enzymes and algicidal substance from heterotrophic bacteria to cope with M. aeruginosa.

\section{Conclusions}

1-hydroxyphenazine had a lytic effect on $M$. aeruginosa cells with a manner independent of ROS level. The reduction of total anti-oxidative capacity and the depletion of GSH might be the important modes by which 1-hydroxyphenazine acted on M. aeruginosa. The extracellular degradative enzymes from heterotrophic bacteria had a weak inhibitory effect on the growth of 
M. aeruginosa and made $M$. aeruginosa suffered oxidative damage. But the addition of extracellular degradative enzymes eventually alleviated the inhibitory effect of 1-hydroxyphenazine on $M$. aeruginosa. More algicidal substances might be needed to deal with $M$. aeruginosa in natural environment with accompanying bacteria. Further investigation of comparative transcriptomics is warranted to make it clearer how the heterotrophic partnership increases the stress resistance of $M$. aeruginosa. It will help us make better use of algicidal substances to eliminate harmful algal blooms.

\section{Acknowledgements}

This research was supported by the National Natural Science Foundation of China (Grant No. 31800426), the Natural Science Foundation of Jiangsu Province (Grant No. BK20181249) and the Jiangsu Agriculture Science and Technology Innovation Fund [Grant No. CX(20)2027].

\section{Conflict of Interest}

The authors declare no conflict of interest.

\section{References}

1. LÜRLING M., VAN OOSTERHOUT F., FAASSEN E. Eutrophication and warming boost cyanobacterial biomass and microcystins. Toxins, 9 (2), 64, 2017.

2. PERRI K.A., SULLIVAN J.M., BOYER G.L. Harmful algal blooms in Sodus Bay, Lake Ontario: A comparison of nutrients, marina presence, and cyanobacterial toxins. J. Great Lakes Res, 41 (2), 326, 2015.

3. MOREIRA C., SPILLANE C., FATHALLI A., VASCONCELOS V., ANTUNES A. African origin and Europe-mediated global dispersal of the cyanobacterium Microcystis aeruginosa. Curr. Microbiol., 69 (5), 628, 2014.

4. KOPYLOV A.I., KOSOLAPOV D.B., MASLENNIKOVA T.S., MYLNIKOVA Z.M. Production of heterotrophic bacterioplankton in a large meso-eutrophic reservoir: the importance of extracellular organic carbon released by phytoplankton. Contemp. Probl. Ecol., 11 (1), 54, 2018.

5. ŠEJNOHOVÁ L., MARŠÁLEK B. Ecology of cyanobacteria II: their diversity in space and time. In Microcystis; Whitton B.A., Eds., Springer: Dordrecht, Netherlands, Volume 7, 195, 2012.

6. LIU L., HUANG Q., QIN B. Characteristics and roles of Microcystis extracellular polymeric substances (EPS) in cyanobacterial blooms: a short review. J. Freshwater Ecol., 33 (1), 183, 2018.

7. SHAO K., ZHANG L., WANG Y., YAO X., TANG X., QIN B., GAO G. The responses of the taxa composition of particle-attached bacterial community to the decomposition of Microcystis blooms. Sci. Total Environ., 488-489, 236, 2014.
8. NATRAH F.M.I., BOSSIER P., SORGELOOS P., YUSOFF F.M., DEFOIRDT T. Significance of microalgalbacterial interactions for aquaculture. Rev. Aquacult., 6 (1), 48, 2014.

9. CAO X., ZHOU Y., WANG Z., SONG C. The contribution of attached bacteria to Microcystis bloom evidence from field investigation and microcosm experiment. Geomicrobiol. J., 33 (7), 1, 2016.

10. SHAO J., JIANG Y., WANG Z., PENG L., LUO S., GU J., LI R. Interactions between algicidal bacteria and the cyanobacterium Microcystis aeruginosa: lytic characteristics and physiological responses in the cyanobacteria. Int. J. Environ. Sci. Te., 11 (2), 469, 2014.

11. ZHANG B.H., DING Z.G., LI H.Q., MOU X.Z., ZHANG Y.Q., YANG J.Y., ZHOU E.M., LI W.J. Algicidal activity of metabolites from Streptomyces eurocidicus JXJ-0089 and their effects in the physiology of Microcystis. Appl. Environ. Microbiology, 82 (17), 5132, 2016.

12. AN X., ZHANG B., ZHANG H., LI Y., ZHENG W., YU Z., FU L., ZHENG T. Discovery of an algicidal compound from Brevibacterium sp. BS01 and its effect on a harmful algal bloom-causing species, Alexandrium tamarense. Fronti. Microbiol., 6, 1235, 2015.

13. PRABHU M.S., WALAWALKAR Y.D., FURTADO I. Purification and molecular and biological characterization of the 1-hydroxyphenazine, produced by an environmental strain of Pseudomonas aeruginosa. World J. Microbiol. Biotechnol., 30, 3091, 2014.

14. PENG H., HUAN Q., BILAL M., WANG W., ZHANG X. Kinetics, mechanism, and identification of photodegradation products of phenazine-1-carboxylic acid. Environ. Technol., 41 (14), 1848, 2020.

15. LI M., NKRUMAH, P.N., PENG Q. Different tolerances to chemical contaminants between unicellular and colonial morph of Microcystis aeruginosa: Excluding the differences among different strains. J. Hazard Mater., 285, 245, 2015.

16. GAO L., PAN X., ZHANG D., MU S., LEE D.J., HALIK U. Extracellular polymeric substances buffer against the biocidal effect of $\mathrm{H}_{2} \mathrm{O}_{2}$ on the bloom-forming cyanobacterium Microcystis aeruginosa. Water Res., 69, $51,2015$.

17. DRAKARE S., LIESS A. Local factors control the community composition of cyanobacteria in lakes while heterotrophic bacteria follow a neutral model. Freshwater Biol., 55 (12), 2447, 2010.

18. KUEHN K.A., FRANCOEUR S.N., FINDLAY R.H., NEELY R.K. Priming in the microbial landscape: periphytic algal stimulation of litter-associated microbial decomposers. Ecology, 95 (3), 749, 2014.

19. SPARBER K., DALTON C., DE EYTO E., JENNINGS E., LENIHAN D., CASSINA F. Contrasting pelagic plankton in temperate Irish lakes: the relative contribution of heterotrophic mixotrophic and autotrophic components and the effects of extreme rainfall events. Waters, 5 (3), 295, 2015.

20. MARIMUTHU D., JAYARAMAN A. Isolation and growth characterization of the fresh water algae Chlorosarcinopsis eremi on different growth media. J. Pure Appl. Microbio., 12 (1), 389, 2018.

21. LEE H.W., PARK B.S., JOO J.H., PATIDAR S.K., CHOI H.J., JIN E., HAN M.S. Cyanobacteria-specific algicidal mechanism of bioinspired naphthoquinone derivative, NQ 2-0. Sci. Rep., 8, 11595, 2018. 
22. MEYER N., BIGALKE A., KAULFUß A., POHNERT G. Strategies and ecological roles of algicidal bacteria. FEMS Microbiol. Rev., 41 (6), 880, 2017.

23. BRUTEMARK A., ENGSTRÖM-ÖST J., VEHMAA A., GOROKHOVA E. Growth, toxicity and oxidative stress of a cultured cyanobacterium (Dolichospermum sp.) under different $\mathrm{CO}_{2} / \mathrm{pH}$ and temperature conditions. Phycol. Res., 63 (1), 56, 2015.

24. CHEN S.M., RAJAJI U., MANI G., CHEN T.W., ALI M.A., AL-HEMAID F.M.A., ELSHIKH M.S., FARAH M.A. Hierarchically structured porous RGO nanosheets/ $\mathrm{CuFe}_{2} \mathrm{O}_{4}$ nanodots composite for sensitive detection of oxidative stress biomarker in biological fluids. Inorg. Chem. Front. 5 (4), 944, 2018.

25. YANG M.K., HUANG H., GE F. Lysine propionylation is a widespread post-translational modification involved in regulation of photosynthesis and metabolism in cyanobacteria. Int. J. Mol. Sci., 20 (19), 4792, 2019.

26. DE PORCELLINIS A.J., NORGAARD H., BREY L.M.F., ERSTAD S.M., JONES P.R., HEAZLEWOOD J.L., SAKURAGI Y. Overexpression of bifunctional fructose-1, 6-bisphosphatase/sedoheptulose-1, 7-bisphosphatase leads to enhanced photosynthesis and global reprogramming of carbon metabolism in Synechococcus sp PCC7002. Metab. Eng., 47, 170, 2018.

27. GRAHAME HARDIE D. Keeping the home fires burning: AMP-activated protein kinase. J. R. Soc. Interface, 15 (138), 20170774, 2018.

28. ZHANG L., HE Y., GOSWAMI N., XIE J., ZHANG B., TAO X. Uptake and effect of highly fluorescent silver nanoclusters on Scenedesmus obliquus. Chemosphere, 153, 322, 2016.

29. YOU B.R., PARK W.H. Suberoyl bishydroxamic acidinduced apoptosis in HeLa cells via ROS-independent, GSH-dependent manner. Mol. Biol. Rep., 40 (5), 3807, 2013.
30. LEE H., LEE D.G. Gold nanoparticles induce a reactive oxygen species-independent apoptotic pathway in Escherichia coli. Colloid. Surface. B, 167, 1, 2018.

31. YANG X., XIE P., YU Y., SHEN H., DENG X., MA Z., WANG P., TAO M., NIU Y. Microcystis aeruginosal Pseudomonas pseudoalcaligenes interaction effects on offflavors in algae/bacteria co-culture system under different temperatures. J. Environ. Sci.-China, 31, 38, 2015.

32. BERNSTEIN H.C., MCCLURE R.S., THIEL V., SADLER N.C., KIM Y.M., CHRISLER W.B., HILL E.A., BRYANT D.A., ROMINE M.F., JANSSON J.K., FREDRICKSON J.K., BELIAEV A.S. Indirect interspecies regulation: transcriptional and physiological responses of a cyanobacterium to heterotrophic partnership. mSystems, 2 (2), e00181-16, 2017.

33. TAKANO H.K., BEFFA R., PRESTON C., WESTRA P., DAYAN F.E. A novel insight into the mode of action of glufosinate: how reactive oxygen species are formed. Photosynth. Res, 144 (3), 361, 2020.

34. GONZÁlEZ A., FILLAT M.F., BES, M.T., PELEATO, M.L., SEVILLA, E. The Challenge of Iron Stress in Cyanobacteria. In Cyanobacteria; Tiwari A., Eds., IntechOpen: London, UK, Volume 6, pp.109, 2018.

35. TAI, V., PAULSEN, I.T., PHILLIPPY, K., JOHNSON, D.A., PALENIK, B. Whole-genome microarray analyses of Synechococcus-Vibrio interactions. Environ. Microbiol., 11 (10), 2698, 2009.

36. PAN X., CAO D., XIE, F., XU F., SU X., MI H., ZHANG X., LI M. Structural basis for electron transport mechanism of complex I-like photosynthetic NAD $(\mathrm{P}) \mathrm{H}$ dehydrogenase. Nat. Commun., 11 (1), 610, 2020.

37. YAMORI W., SHIKANAI T. Physiological functions of cyclic electron transport around photosystem I in sustaining photosynthesis and plant growth. Annu. Rev. Plant Biol., 67 (1), 81, 2016. 
